\title{
Odontogenic Myxoma of the Mandible
}

\author{
Ramya Sree S ${ }^{1}$, Vardendra G Kulkarni ${ }^{2}$, Chandrashekhar $\mathrm{HR}^{3}$, Shivamurthy $\mathrm{KC}^{4}$
}

Quick Response Code

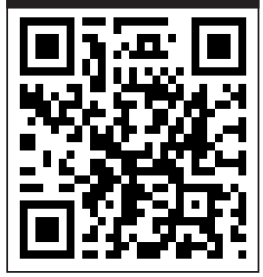

doi : 10.5866/2017.9.10101

1Post-Graduate Student

${ }^{2}$ Associate Professor

${ }^{3}$ Professor

Department of Pathology, J J M Medical College,

Davangere

${ }^{4}$ Professor

Department of Plastic Surgery, SS institute of

Medical Sciences and Research Centre, Davangere

\section{Article Info:}

Received: April 12, 2017

Review Completed: May 11, 2017

Accepted: J une 13, 2017

Available Online: J une, 2017 (www.nacd.in)

(c) NAD, 2017 - All rights reserved

Email for correspondence:

dr.ramya0705@gmail.com

\begin{abstract}
:
Background: Odontogenic myxoma is a rare slow growing, benign, locally aggressive tumor of ectomesenchymal origin with or without odontogenic epithelium, comprising $3 \%$ to $6 \%$ of all odontogenic tumors. It appears to originate from dental papilla, follide, or periodontal ligament in mandible and less commonly the maxilla. These usually present in second or third decades with marked female predilection and have recurrence rates of approximately $25 \%$.
\end{abstract}

Case report: A 22 year ol d female presented with swelling over the left lower jaw region for 1 year, showing facial deformity and slow progression in size. On examination, a bony hard, nontender, fixed mass of size $7 \times 5 \mathrm{~cm}$ was seen on the body of left mandible. Intraoral examination, a mass extending to the floor of mouth on left side, obstructing the left gingivo-labial sulcus noted. Orthopantomogram (OPG) of left mandible showed multicystic, radiolucent tumor involving outer and inner table of body of the mandible. A clinical diagnosis of Amel oblastoma was made. Left hemimandibulectomy with reconstruction was done. On gross examination, hemi-mandibulectomy specimen with teeth attached measured about $6 \times 6 \times 4.5 \mathrm{~cm}$ in size and cut surface was grey white, hard in consistency with mucoid secretions. Microscopically, a diagnosis of Odontogenic myxoma was made.

Conclusion: Due to its variable clinico-radiographic characteristics and propensity for recurrence, correct histopathological diagnosis is required for adequate management.

Key words: Myxoma, odontogenic tumors, recurrence.

\section{Introduction:}

Myxoma is defined as "a tumor composed of sometimes spindle-shaped cells set in a myxoid stroma containing mucopolysaccharide, through which course very delicate reticulin fibers in various directions and which is locally invasive." Myxomas were first described by Virchow in 1871. Myxoma of the jaws was identified by Thoma in 1954, but epidemiologic data is scarce. ${ }^{1}$ Myxoma occurs both in bone and soft tissue. Although intraosseous myxoma has been reported in various anatomical sites the majority of these tumors occur in the mandible, followed by the maxilla. Hence the term "odontogenic myxoma" (OM) is often applied when the tumor occurs in the jaws to reflect its odontogenic origin. ${ }^{2}$ 
Odontogenic myxomas are rare slowly growing benign tumors derived from embryonic mesenchymal elements of dental anlage that represents about 3\% of all odontogenic tumors with high recurrence rate. ${ }^{2,5}$

According to the World Health Organization (WHO), OM is classified as benign tumor of ectomesenchymal origin with or without odontogenic epithelium. OM appears to originate from dental papilla, follicle, or periodontal ligament. The evidence for its odontogenic origin arises from its almost exclusive location in the tooth bearing areas of the jaws, its occasional association with missing or unerupted teeth, and the presence of odontogenic epithelium. ${ }^{4,6}$

The odontogenic nature of the myxomas has been challenged by some authors because of the appearances, whilst consistent with odontogenic ectomesenchyme, could also represent a more primitive fibroblastic or undifferentiated tissue. ${ }^{7}$ Most of the OMs reported wereyoung adults affected mostly in their second and third decade of life with marked female predilection.2, 4, 6,7 Clinically, OMs are slow growing, painless, and locally aggressive tumors. Since pain and hypoesthesia are not common, the lesions may reach a considerable size before patient perceives its existence and seeks treatment. Larger lesions may cause tooth displacement and cortical bone expansion. ${ }^{7,8}$

Radiologically, the appearance may vary from a uni locular radiol ucency to a multicysticlesion with well-defined or diffuse margins with fine, bony trabeculae within its interior structure expressing a "honey combed," "soap bubble," or "tennis racket" appearance. ${ }^{4,9} \mathrm{~A}$ unilocular appearance may beseen more commonly in children and in anterior parts of the jaws. Root resorption is rarely seen, and the tumor is often scalloped between the roots. ${ }^{8}$

OMs are not encapsulated, thus promoting significant infiltration into the adjacent medullar bone. ${ }^{7}$ It can be locally aggressive despite its slow growth, which is reflected in the fact that less than $1 \%$ of tumor cells are positive for the proliferation marker Ki-67.2 The OM exhibits abundant extracellular production of ground substance and thin fibrils by the delicate spindle-shaped cells.
These undifferentiated mesenchymal cells are capable of fibroblastic differentiation also. Depending upon the pattern of differentiation, the histological nature of the tumor varies. It may be completely myxomatous tissue or varying proportions of myxomatous and fibrous tissue., 7 Somestudies show OM as a modified form of fibroma in which myxoid intracellular substance separates the connective tissue. ${ }^{4,10}$

The treatment of choice for OM is surgical excision by enucleation, curettage, or block resection. ${ }^{7}$ Although small myxomas are generally treated by curettage, larger lesions require extensive resection. Since myxomas tend to recur, it is mandatory that the patients be carefully followed after the surgery. It is widely accepted that local infiltration accounts for its aggressive nature and high recurrence rate, resulting in sparsely scattered deposits of residual bone and dystrophic mineralization in the tumor stroma. ${ }^{2}$

Due to poor follow-up and lack of reports, a precise and accurate recurrence rate is still missing. The high recurrence rate of $25 \%$ is reported when more conservativetreatments are used. ${ }^{7}$ The present case is discussed due to its rarity, large size, mandibular involvement, diagnostic and operative dilemmas encountered during its management.

\section{Case Report:}

A 22 year old female was admitted to department of Plastic surgery with complaints of swelling over the left lower jaw region for 1 year, showing facial deformity and slow progression in size. It was insidious in onset and associated with occasional pain over the swelling. On extraoral examination, a bony hard mass of size $7 \times 5 \mathrm{~cm}$ was seen on the body of the left mandible, fixed to the mandible, non-tender with no local rise of temperature. Intraoral examination revealed a mass extending to the floor of mouth on left side, obstructing the left gingivo-labial sulcus and left 2nd molar tooth with caries noted. Radiological investigations-

OPG and X-Ray of left mandible showed tumor involving body of the mandible. It was multicystic, radiolucent tumor involving outer and inner table of body of the mandible. 


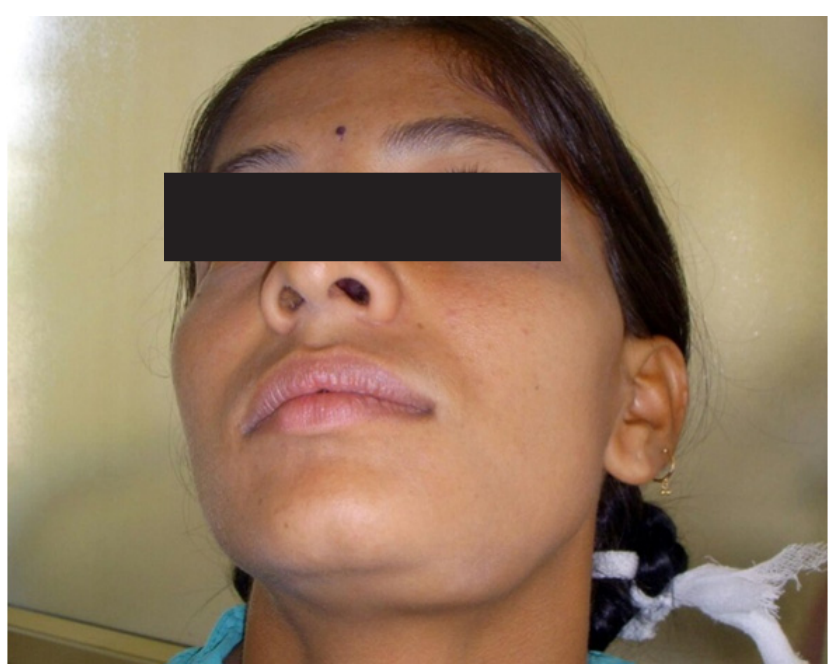

Figure 1: Extraoral photograph, showing swelling in the Left-side Body of the mandible

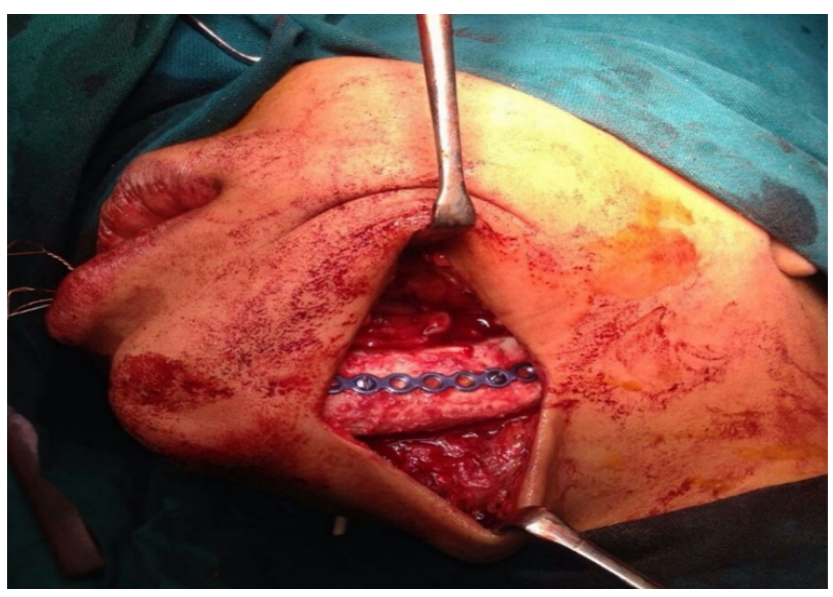

Figure 3: Postoperative picture showing reconstruction of the resected site with iliac bone grafting and fixation with titanium plate.

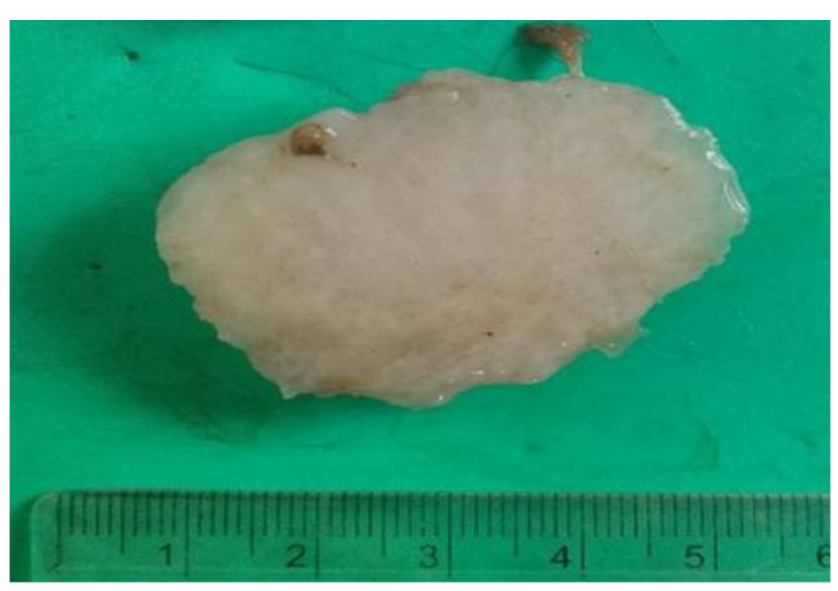

Figure 5: Cut-surface showing grey white lesion with mucoid secretions

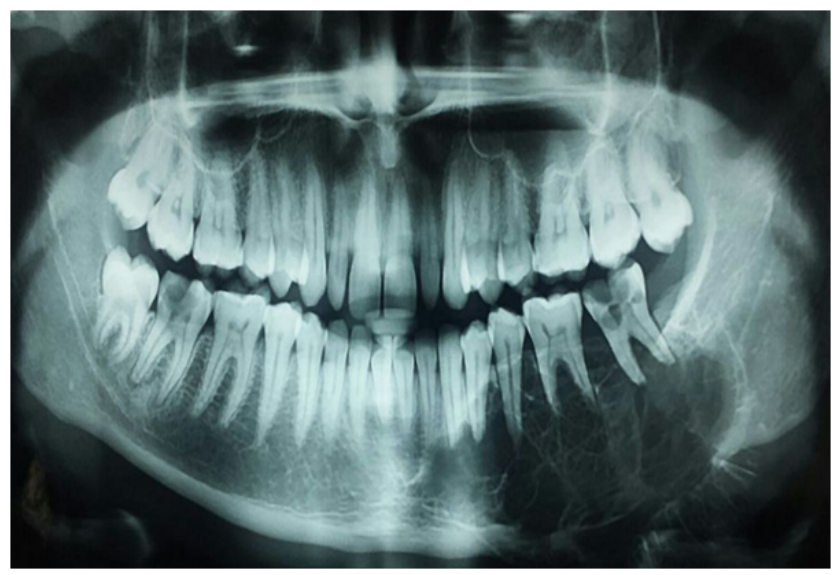

Figure 2: Panoramic radiograph showed a poorly defined, multilocular radiolucent lesion with "soap bubble" appearance on left side mandible

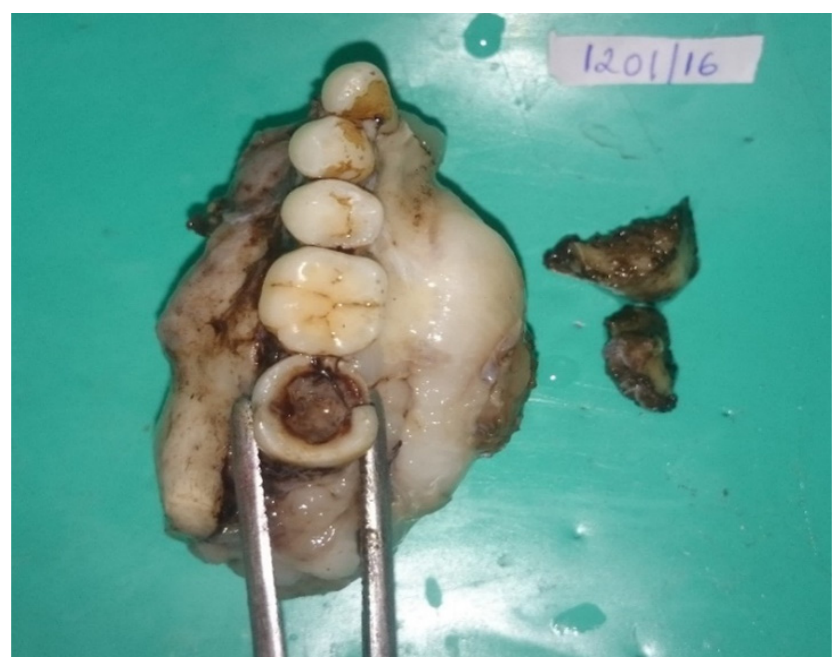

Figure 4: Gross specimen of hemi-mandibulectomy with teeth attached measuring $6 \times 6 \times 4.5 \mathrm{~cm}$. Left 2nd molar tooth showing dental caries.

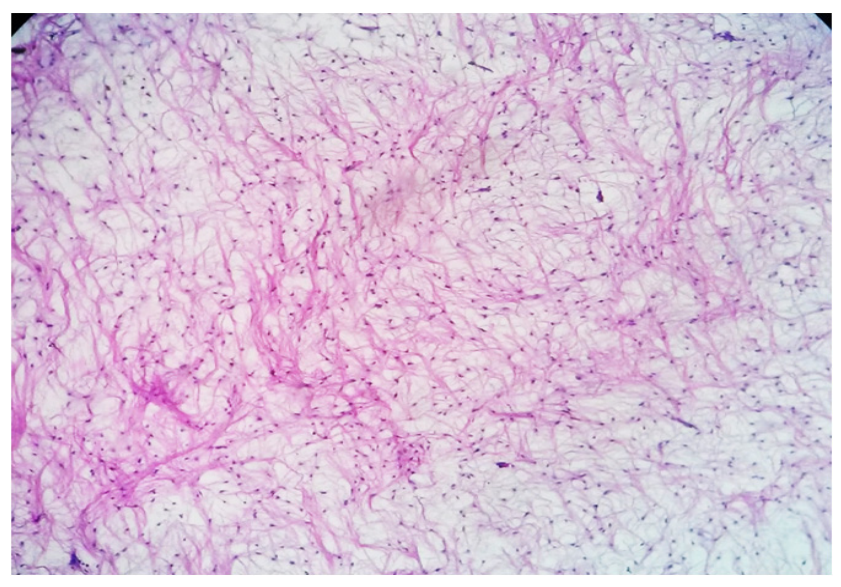

Figure 6: Microscopic examination showing stellate and spindle shaped cells having round to oval vesicular nuclei with eosinophilic cytoplasmic processes, embedded in myxoid stroma. $(H \& E, x 40)$ 
A clinical diagnosis of Ameloblastoma was made and the patient was operated with Left side hemimandibulectomy with reconstruction of mandible with bonegrafting from I liac crest and the specimen was sent for histopathological examination. Postoperative recovery was excellent.

Grossly the hemi-mandibulectomy specimen with teeth attached was $6 \times 6 \times 4.5 \mathrm{~cm}$ and on cutsurface, was grey white, hard in consistency with mucoid secretions.

Microscopic examination showed stellate and spindle shaped cells having round to oval vesicular nuclei with eosinophilic cytoplasmic processes, embedded in myxoid stroma. Few thin walled vascular spaces were seen interspersed between the tumor cells.

\section{Discussion:}

$\mathrm{OM}$ is a rare aggressive intraosseous lesion derived from embryonic mesenchymal tissue associated with odontogenesis and primarily consisting of a myxomatous ground substance with widely scattered undifferentiated spindled mesenchymal cells. Though it is a benign neoplasm, it may be infiltrative, aggressive and may recur. ${ }^{4}$

The prevalence of OM is principally quoted between $0.04 \%$ and $3.7 \%$. In Asia, Europe, and America, relative frequencies between $0.5 \%$ and $17.7 \%$ have been reported..$^{5,7}$ There was lack of uniformity in the most common age group studies, but most of the studies showed an age range of 22.7 to 36.9 years, and it is rarely seen in patients younger than 10 years of age or older than $50,4,7$ In the present case age of the patient is 22 years, which is in conformity with the reported literature.

The mandible appears to be more frequently affected than the maxilla.2,4,8 The present case involves posterior mandible, which is almost in conformity with the reported literature. There are no clinical or radiological signs that would allow a physician to distinguish myxoma from odontogenic and non-odontogenic lesions; however, histological analysis shows several lesions that could be misinterpreted as myxoma. ${ }^{7}$

The majority of the myxomas are al most al ways asymptomatic, although some patients present with progressive pain in lesions invading into surrounding structures with eventual neurological disturbances.OM of the maxilla is less frequent but behaves more aggressively than that of the mandible. ${ }^{7}$ In the present case the patient complained of intermediate pain, and was more aggressive, in spite of its mandibular occurrence.

OMs radiographically appear as multilocular or unilocular radiolucencies. The present case showed multilocular radiolucency with "soap bubble" appearance. Differential diagnosis like amel oblastoma, ameloblastic fibroma, odontogenic fibroma, central hemangioma, or odontogenic keratocyst along with OM could be listed as initial diagnostic hypothesis based on the clinical and radiological findings. $2,4,7$

The aggressive nature of OM is well documented in the literature. The tumor is not radiosensitive, and surgery is the treatment of choice. ${ }^{2,4,6,8}$

The lack of a capsule and infiltrative growth pattern is responsible for high rate of recurrence when conservative enucleation and curettage are performed. Recurrence is minimized with extensive partial or total resection procedures. ${ }^{2,11}$ The conservative treatments have several advantages over more radical treatment, which would consist of mandibular reconstruction with fibular microsurgical flap. The treatment represents a less morbid intervention with the possibility of intraoral access, the absence of donor area, a shorter hospitalization time, not interfering with facial growth in children, and a low procedural cost. Radical treatment of block resection is advised by most authors over conservative treatment due to its invasive nature, large size, and recurrence history even though this intervention poses patients post treatment rehabilitation difficulties. ${ }^{4,7,9}$

The present case was treated with block resection as left side hemi-mandibulectomy with reconstruction of mandible with bone grafting from Iliac crest. A minimum of five years of surveillance is required to confirm that the lesion has healed, and periodical clinical and radiographic followup should be maintained indefinitely irrespective of treatment modality applied to treat OM. ${ }^{7}$ 
Acknowledgements: Thankful to the technical staff at department of Pathology, JJ M Medical college, Davangere.

Conflict of Interest statement: Nil

\section{REFERENCES:}

1. Halfpenny W, Verey A, Bardsley V. Myxoma of the mandibular condyle: $A$ case report and review of the literature. Oral Surg Oral Med Oral Pathol Oral Radiol Endod 2000; 90(3):348-53.

2. Lin $Y L$, Basile J R. A Case of odontogenic myxoma with unusual histological features mimicking a fibro-osseous process. Head Neck Pathol 2010; 4(3):253-6.

3. Abiose BO, Ajagbe HA, Thomas O. Fibromyxomas of the jawbones-A study of ten cases. Br J Oral Maxillofac Surg 1987; 25(5):415-21.

4. Sivakumar G, Kavitha B, Saraswathu TR, Sivapathasundharam B. Odontogenic myxoma of maxilla. Indian J Dent Res 2008; 19(1):62-5.

5. Lu Y, Xuan M, Takata T, Wang C, He Z, Zhou Z et al., "Odontogenic tumors: a demographic study of 759 cases in a Chinese population". Oral Surg Oral Med Oral Pathol Oral Radiol Endod 1998; 86:707-14.
6. Reddy SP, Naag A, Kashyap B. Odontogenic myxoma: Report of two cases. Natl J Maxill ofac Surg 2010; 1(2):1836.

7. Manne RK, Kumar V, Sarath PV, Anumula L, Mundlapudi S, Tanikonda R. Case Report Odontogenic Myxoma of the Mandible 2012; 4-7.

8. Spencer KR, Smith a. Odontogenic myxoma: case report with reconstructive considerations. Aust Dent J 1998; 43(4):20912.

9. Singaraju S, Wanjari SP, and Parwani RN. "Odontogenic myxoma of the maxilla: a report of a rare case and review of literature". J Oral Maxillofac Pathol 2010; 14:19-23.

10. Adekeye EO, Avery BS, Edwards MB, Williams HK. Advanced central myxoma of the jaws in Nigeria. Clinical features, treatment and pathogenesis. Int J Oral Surg. Munksgaard I nternational Publishers Ltd. 1984; 13(3):17786.

11. Simon ENM, Merkx MAW, Vuhahula E, Ngassapa D, Stoelinga PJ W. Odontogenic myxoma: A clinicopathological study of 33 cases. Int J Oral Maxillofac Surg 2004; 33(4):333-7.

\section{Gain quick access to our journal online View our journal at www.nacd.in}

